\title{
CORRESPONDENCE
}

\section{VALIDITY OF NECK STIFFNESS AS A PREDICTOR FOR DEATH FROM TETANUS}

\author{
Re: "Identification of risk factors for death from tetanus in Pernambuco, Brazil: a case control study"
}

Uberlândia, January 15, 2001

\section{Sir,}

I congratulate Dr. Miranda-Filho and his colleagues for their case-control study aimed at recognising risk factors for death from tetanus ${ }^{3}$. Taking advantage of the available hospital records of 485 non-paediatric cases of tetanus admitted to a single reference hospital in Pernambuco during a 6year period, they carried out a study comparing the individuals who died from tetanus with a sample of survivors. They undertook an analytical epidemiological study from material that is usually reported only descriptively as case series. Case reports and case series are often considered as second class studies, although valuable information can be obtained from these studies ${ }^{2,4}$. Miranda-Filho's study is a good example of efficiently using available hospital data for attempting to answer questions of clinical and public health interest.

Having in mind that the identification of risk factors for death from tetanus was the main objective of Miranda-Filho and colleagues' study, I was surprised that they assessed whether neck stiffness was a predictor for death. Neck stiffness is a common finding of patients with generalised tetanus $s^{1,6}-$ in my experience it is found in the large majority of them - and therefore should not be expected to be a risk factor for death from this disease. More puzzling still was to find out that neck stiffness was actually shown to be a significant predictor for death from tetanus in the Pernambuco's study population even after adjustment for confounders by multivariate analysis. The validity of this finding deserves comment.

A drawback of retrospective studies that abstract previously collected data from medical files is that some of the information of interest for the study may be missing in some charts because it was not recorded. As pointed out by Miranda-Filho and colleagues, if missing information was randomly distributed, information bias would occur to a known direction, towards the null, i.e. to no association between exposure and outcome. In other words, a possible association between "exposure" (presence of neck stiffness) and outcome (death) would be underestimated. However, in the case of neck stiffness, it is doubtful that misclassification of exposure was non-differential. Severe cases tend to be better documented as to clinical findings and laboratory tests than milder cases. Non-differential misclassification of exposure (as it is called in the epidemiological parlance) can bias the relative risk estimate to any direction ${ }^{5}$. In the case of neck stiffness, presuming that it was under-recorded in milder cases, an overestimation of its role as a predictor for death from tetanus would occur. I therefore believe that one has to be very cautious before accepting that the presence of neck stiffness in tetanus patients is a predictor for death. It is my impression that in Miranda-Filho's study, due to misclassification of exposure, neck stiffness is actually only a marker of severity of disease.

\section{REFERENCES}

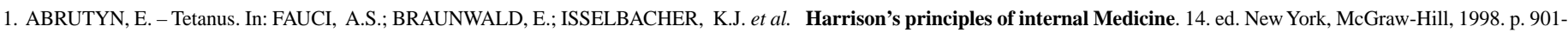
904

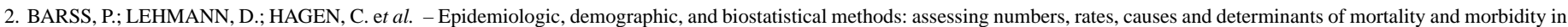
developing areas. In: PICKERING, J.L., ed. Health research for development: a manual. Montreal, Canadian University Consortium for Health in Development, 1997. p. 48-100.

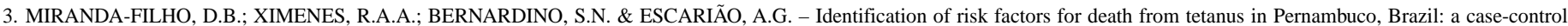
study. Rev. Inst. Med. trop. S. Paulo, 42: 333-339, 2000.

4. NISHIOKA, S.A. - Traditional case reports still have a role. West. J. Med., 171: 226, 1999.

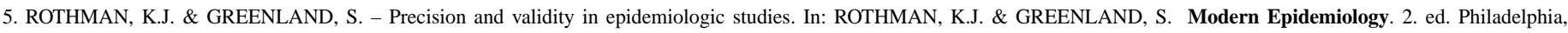
Lippincott-Raven, 1998. p. 115-134.

6. WEINSTEIN, L. - Tetanus. In: FEIGIN, R.D. \& CHERRY, J.D. Textbook of pediatrics infectious diseases. 2. ed. Philadelphia, W.B. Saunders, 1987. p. 1126-1134.

Sérgio de Andrade Nishioka

Faculdade de Medicina Universidade Federal de Uberlândia

Uberlândia, MG, Brasil snishioka@umuarama.ufu.br 